\title{
Identificação do papilomavírus humano em doentes com carcinoma de células escamosas do canal anal e sua relação com o grau de diferenciação celular e estadiamento
}

\author{
Identification of human papillomavirus in patients with anal squamous cell \\ carcinoma and its relation with the grade of cellular differentiation and staging
}

PAULO CARDOSO SOARES ${ }^{1}$, SILVANEIDE FERREIRA², LUISA LINA VILLA ${ }^{3}$, DELCIO MATOS ${ }^{4}$

\begin{abstract}
${ }^{1}$ Mestre em Medicina pela Universidade Federal de São Paulo (Unifesp) - São Paulo (SP); Titular do Departamento de Cirurgia Abdominopélvica do Hospital Ophir Loyola (HOL); Professor-Assistente da Disciplina de Clínica Cirúrgica da Universidade do Estado do Pará (Uepa) - Belém (PA), Brasil; Especialização em Coloproctologia no ST. Mark's Hospital de Londres. ${ }^{2}$ Graduação em Biologia pela Universidade Camilo Castelo Branco; Técnico de Pesquisa Sênior do Instituto Ludwig de Pesquisa sobre o Câncer - São Paulo (SP), Brasil. ${ }^{3}$ Doutora em Ciências Biológicas pela Universidade de São Paulo (USP); Chefe do Grupo de Virologia do Instituto Ludwig de Pesquisa sobre o Câncer; Membro da Academia Brasileira de Ciências; Comendadora da Ordem Nacional do Mérito Científico - São Paulo (SP), Brasil. ${ }^{4}$ Mestre e Doutor em Medicina; Professor Titular; Livre-Docente da Disciplina de Gastroenterologia Cirúrgica da Coordenador do Programa de Pós-graduação em Gastroenterologia Cirúrgica da Escola Paulista de Medicina da Universidade Federal de São Paulo (EPM-Unifesp) - São Paulo (SP), Brasil; Pós-Doutorado no ST. Mark's Hospital - Londres.
\end{abstract}

SOARES PC, FERREIRA S, VILLA LL, MATOS D. Identificação do papilomavírus humano em doentes com carcinoma de células escamosas do canal anal e sua relação com o grau de diferenciação celular e estadiamento. Rev bras Coloproct, 2011;31(1): 8-16.

RESUMO: Objetivo: Identificar os tipos de papilomavírus humano (HPV) nos portadores de carcinoma do canal anal (CCA), relacionando-os ao grau de diferenciação celular e estadiamento da lesão, em pacientes do Belém, Pará, entre 1998 e 2000. Métodos: Foi realizado um estudo de caso-controle com 75 pacientes, divididos em: Grupo Teste, com 33 portadores de carcinoma do canal anal, e o Grupo Controle, com 42 portadores de doenças não-neoplásicas do canal anal. Os tipos virais foram identificados por PCR e dot blot. $\mathrm{O}$ teste exato de Fischer foi utilizado para avaliar a ocorrência de HPV. Adotou-se a tabela de contingência 3x2 para representar a distribuição dos tipos de HPV. Nos testes de hipóteses, foi prefixado o nível de significância $\alpha=0,05$ para a rejeição da hipótese de nulidade. Resultados: A prevalência do HPV foi significante entre os Grupos Teste (60,6\%) e Controle (26,2\%) $(p=0,0027)$. Os tipos virais mais comuns foram $16(42,4 \%)$ e $18(15,2 \%)$. Observaram-se diferenças entre grupos na prevalência do HPV 16 (p=0,027) e 18 (p=0,043) no Grupo Teste, e o tipos $16(19,0 \%$, ) e 18 em $(2,4 \%)$ no Grupo Controle. No Grupo Teste, avaliouse a distribuição dos tipos de HPV em relação ao estadiamento e ao grau de diferenciação celular, não apresentando diferenças estatisticamente significativas. Conclusão: $O$ carcinoma de células escamosas do canal anal está associado à presença de HPV, e os tipos 16 e 18 são os mais frequentes.

Palavras-chave: infecções por papilomavírus; carcinoma de células escamosas; canal anal; papiloma.

Trabalho realizado no Departamento de Cirurgia Abdominopélvica do Hospital Ophir Loyola da Universidade do Estado do Pará e no Instituto Ludwig de Pesquisa sobre o Câncer.

Recebido em: $23 / 11 / 2010$

Aprovado em: 14/04/2011 


\section{INTRODUÇÃO}

O carcinoma de células escamosas (CCE) do canal anal é um tumor raro, embora desde 2002 tenha sido referido o aumento de sua incidência nos Estados Unidos, na Suécia e na Dinamarca ${ }^{1}$.

De fato, tem-se constatado o aumento dos casos desses tumores, principalmente na população do gênero masculino, constituída por homossexuais e bissexuais, particularmente aqueles infectados pelo vírus da imunodeficiência humana (HIV), e nos pacientes imunossuprimidos quimicamente. Há também relatos da elevada ocorrência entre homens e mulheres com atividades sexuais promíscuas ${ }^{2-4}$.

Atualmente, a etiologia parece estar bem elucidada quanto à participação do papilomavírus humano (HPV) na gênese desse tumor ${ }^{1,5-7}$. Dados epidemiológicos, baseados em estudos controlados, têm demonstrado que, na maioria dos casos, esse tipo de neoplasia decorre de infecções adquiridas na mucosa anal, transmitidas por meio de relações sexuais pelos tipos de HPV já bastante conhecidos e delineados nos estudos sobre câncer do colo uterino ${ }^{8}$.

O tratamento padrão consiste na combinação de radioterapia e quimioterapia, sendo a cirurgia amputativa realizada apenas nos casos de ausência de resposta, de comprometimento importante dos esfíncteres do canal anorretal, de tumor residual e de recidiva ${ }^{1}$.

Os CCE do canal anal são considerados neoplasias de crescimento agressivo, as quais invadem com muita frequência os músculos que compõem o aparelho esfincteriano, com capacidade de promover metástases a distância. Quanto ao tratamento e prognóstico, tumores que se localizam na margem do ânus têm tratamento e prognóstico semelhantes aos de outras localizações da pele, sugerindo que a margem anal é um limite essencial de referência tanto para a terapêutica quanto para a sobrevida dos pacientes portadores dessas neoplasias ${ }^{1,9-11}$.

Como resultados dos recentes avanços em Biologia Molecular, mais de 100 tipos de HPV foram identificados e classificados com base nas diferentes composições de DNA ${ }^{12-14}$.

Aproximadamente, 40 tipos, correlacionados com infecções em mucosas genitais, são divididos em: baixo - HPV 6, 11, 42, 43, 44, 54,55, 61, $62,64,67,69,70,71,72,81,83$, e 89 - e alto risco oncológico - HPV 16, 18, 31, 33, 35, 39, 45, 51, 52, $53,56,58,59,66,68,73$ e $82^{15}$. Inúmeros estudos têm demonstrado a relação da infecção do HPV com o epitélio do trato anogenital, em particular com o colo uterino, e alguns trabalhos ressaltam a presença de DNA do HPV de alto e baixo risco em $90 \%$ de $\mathrm{CCE}$ ou $\mathrm{CE}^{16}$.

Da mesma forma, vários estudos têm demonstrado que neoplasias localizadas na região anal também estão infectadas por HPV. A presença destas partículas virais nessa localização anatômica é pertinente, se for considerada a aparência histológica semelhante entre a cérvix e o canal anal. Ambos derivam da mesma membrana cloacal (ectoderma) no embrião, apresentando junção escamocolunar e zona de transição, o que leva a crer que os tecidos são particularmente suscetíveis à infecção por esses vírus ${ }^{4,5,11,16,17}$. Durante os últimos 30 anos, extraordinários progressos foram obtidos para o entendimento da patogênese do CCE. Atualmente, pode-se dizer que trata-se, em muitos casos, de uma doença sexualmente transmitida, a qual pode ser curada usando-se uma combinação de radioterapia e quimioterapia. Alguns pontos da biologia desses tumores estão sendo elucidados, como, por exemplo, o mecanismo molecular envolvendo a resistência à quimiorradiação. A influência das infecções por HIV na progressão tumoral representa área de intensa investigação. O aumento da sobrevida destes pacientes, proporcionado por esquemas terapêuticos mais eficientes, os torna uma população de risco para essa neoplasia ${ }^{11,18-21}$.

O câncer do canal anal é uma neoplasia rara, e, no Brasil, sua frequência não é conhecida com exatidão. As estatísticas nacionais a incluem nas ocorrências de cólon e reto ${ }^{22}$.

\section{MÉTODOS}

Os pacientes tiveram conhecimento do protocolo de estudo e assinaram o termo de consentimento livre e esclarecido, concordando em participar da pesquisa.

O estudo foi realizado no período de janeiro de 1998 a dezembro de 2000, utilizando dois grupos: o Grupo Teste (GT) e o Grupo Controle (GC), com pacientes provenientes do Hospital Ophir Loyola (HOL), em Belém, no Pará. 
Foi elaborada uma ficha para obtenção dos dados clínicos e laboratoriais de cada paciente envolvido no estudo.

A amostra foi constituída por 75 pacientes de ambos os gêneros, sendo 27 do sexo masculino e 48 do feminino, na faixa etária de 18 a 66 anos, dividida em dois grupos: o GT, formado por 33 biópsias de pacientes com câncer do canal anal na faixa etária de 18 a 62 anos (média 48,5), sendo 26 do sexo feminino e sete do masculino; o GC, constituído por espécimes cirúrgicos de 42 pacientes operados por lesões benignas do canal anal, dos quais 22 eram do sexo feminino e 20 do masculino, na faixa etária de 23 a 66 anos (média 41,1), portadores de patologias não-tumorais e que não apresentavam lesões com características de pré-malignidade.

Procedeu-se à pesquisa do DNA viral, por reação em cadeia da polimerase (PCR), e à tipagem do HPV por hibridização em pontos (dot blot) nos dois grupos.

Do GT, foram excluídos os portadores de CCE do canal anal associado a outras neoplasias e/ou doença inflamatória intestinal, e do GC, as biópsias em que coexistiam lesões malignas ou pré-malignas.

Os dois grupos de pacientes foram pareados no ingresso ao protocolo de pesquisa, conforme a idade e o sexo.

$\mathrm{Na}$ análise da amostra do GT, foram considerados para apreciação o gênero e a faixa etária e, em relação à lesão neoplásica, foram definidos a localização, o grau de diferenciação celular e o tamanho do tumor, de acordo com a classificação TNM. Já no GC, foram levantados dados relativos à idade, ao gênero e ao tipo de lesão histológica.

O estadiamento histopatológico foi realizado criteriosamente por três patologistas do HOL para excluir dúvidas quanto ao diagnóstico ou estadiamento. Foram observadas as seguintes varáveis: grau de diferenciação celular segundo a classificação de Broders; estadiamento da doença conforme a classificação TNM, em estádios I, II, IIIa, IIIb e IV; pesquisa e tipagem do HPV de acordo com o protocolo de extração de DNA, do Instituto Ludwig de Pesquisa sobre Câncer.

Foram colhidos fragmentos com uma pinça de haste longa de $20 \mathrm{~cm}$, tipo saca-bocado, utilizada em biópsias cervicais, por meio do exame de retossigmoidoscopia. Em seguida, o material foi imerso em for- mol a $10 \%$ e enviado ao Laboratório de Patologia Clínica do HOL. O produto da biópsia foi acompanhado pela ficha clínica do paciente.

Após a coleta, as amostras de tecido neoplásico foram imediatamente imersas em solução de formol, tamponado a $10 \%$, para evitar a degradação do DNA, e foram encaminhadas à Divisão de Patologia do HOL. Os espécimes fixados pelo formol foram incluídos em parafina e processados por técnica histopatológica padrão.

A avaliação diagnóstica foi realizada por patologistas da instituição: as amostras de pacientes diagnosticados com CCE foram selecionadas para a pesquisa, e os blocos de parafina, enviados para o Instituto Ludwig em São Paulo para extração e tipagem do DNA do HPV, contendo apenas o número de identificação de cada bloco.

A análise estatística teve o objetivo de identificar padrões quantitativos que caracterizassem a presença do HPV e seus tipos nos GT e GC. Internamente no GT, avaliou-se a distribuição dos tipos de HPV em relação ao estadiamento e grau de diferenciação celular. Foram aplicados métodos estatísticos descritivos e inferenciais. Para os testes de hipóteses, foi prefixado o nível de significância $\alpha=0,05$ para rejeição da hipótese de nulidade. $\mathrm{O}$ teste exato de Fisher foi utilizado para testar a ocorrência de HPV entre os GT e GC. A distribuição dos tipos de HPV em função do estadiamento da doença foi apresentada descritivamente com todos os níveis de estadiamento (I, II, IIa e IIb). Entretanto, para realizar os testes de hipótese com maior robustez, em virtude da presença de várias categorias com valor zerado, optou-se por agrupar os níveis de estadiamento em tabelas de contingência $3 \times 2$, que representassem a distribuição dos tipos de HPV entre as duas categorias de estadiamento: I e II (doença menos grave) e IIIa e IIIb (doença mais grave). Para avaliar a associação entre a ocorrência dos tipos de HPV e os graus de diferenciação celular, foi apresentada a distribuição dos tipos de HPV em todos os graus (I, II, III e IV). Entretanto, para tornar possível a realização dos testes de hipóteses, visto que várias categorias ficaram sem ocorrência, foram montadas tabelas de contingência $3 \times 2$ que representassem a distribuição dos tipos de HPV entre as duas categorias de diferenciação celular: graus I e II (doença menos grave) e graus III e IV (doença mais grave). 
Logo, nesses casos, foi aplicado um método nãoparamétrico, o teste do qui-quadrado para comparar e avaliar a diferença entre as duas proporções ${ }^{23}$. Para estimar o intervalo de confiança da prevalência do HPV e do HPV tipo 16, aplicou-se uma estimação de parâmetros para populações binomiais, os cálculos do intervalo de confiança foram feitos com base na aproximação da binomial para curva normal ${ }^{23}$. A prevalência dos HPV tipos 18, 6, 66, 31 e 35 não foi estimada, porque não satisfizeram à condição $\mathrm{npq}>5$. O processamento estatístico foi realizado sob o suporte computacional do pacote bioestatístico BioEstat, versão 4. Os valores significantes foram assinalados por asterisco.

\section{RESULTADOS}

Dos 33 indivíduos do GT, houve maior ocorrência no sexo feminino, $78,8 \%$, contra $21,2 \%$ no masculino. Avaliando-se as diferenças das proporções entre os GT e GC, constata-se associação significativa com tendência de maior ocorrência de câncer no sexo feminino (valor de $\mathrm{p}=0,0338<0,05$ ).

Na variável idade, obteve-se valor de p de 0,2123 , não-significativo, indicando que não há diferença real entre as médias das idades nos GT e GC.

O HPV positivo obteve um valor de $\mathrm{p}$ significante $(0,0027)$, indicando que há real diferença nas proporções entre os grupos. Pode-se afirmar que o HPV positivo ocorre em maior proporção no GT, com $60,6 \%$, contra $26,2 \%$ no GC.

O HPV tipo 16 ocorre em maior proporção no GT (42,4\%). Neste, ocorre apenas em 19\%. Avaliando-se as proporções entre os grupos, o valor de $\mathrm{p}$ do HPV tipo 16 é significante $(0,0273)$, o que indica uma diferença real nas proporções entre os dois grupos. Portanto, os indivíduos infectados pelo HPV tipo 16 se encontram em significativa maioria no GT. Para o HPV tipo 18, a interpretação é a mesma, havendo maior ocorrência significativa no GT $(15,2 \%)$ contra $2,4 \%$, no GC.

Em relação às proporções entre os dois grupos para o HPV, categorizado como "HPV outro tipo", as diferenças não foram significantes (Tabela 1).

Conforme pode ser observado na Figura 1, no GT, a estimativa pontual de prevalência do $\mathrm{HPV}=0,606$, com intervalo de confiança (IC) de $95 \%=[0,439,0,773]$, portanto, existe $95 \%$ de confiança de que entre 43,9 e $77,3 \%$ dos indivíduos com câncer apresentem HPV. Ao IC 99\%=[0,387, 0,826], aplica-se o mesmo raciocínio. Neste mesmo grupo, a prevalência do HPV tipo 16 é igual a 0,425 com IC $95 \%=[0,256-0,646]$. Dessa forma, estima-se, com $95 \%$ de confiança, que, entre 25,6 e $64,6 \%$ dos indivíduos com câncer, apresentam HPV tipo 16.

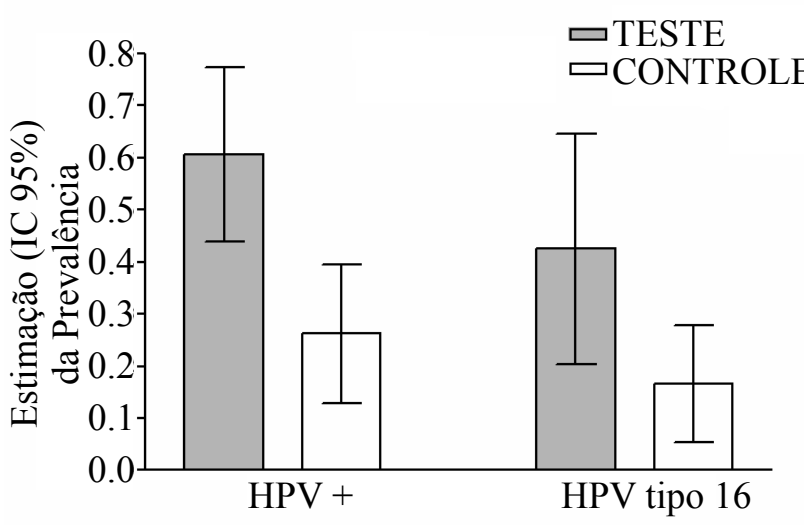

Figura 1. Prevalencia do HPV e do HPV tipo 16 nos Grupos Teste e Controle.

Tabela 1. Tipos do HPV nos Grupos Teste e Controle de amostras coletadas de pacientes do serviço de cirurgia abdominopélvica do HOL em Belém - janeiro de 1998 a dezembro de 2000.

\begin{tabular}{lccccc}
\hline & \multicolumn{3}{c}{ Teste } & \multicolumn{3}{c}{ Controle } & \multirow{2}{*}{ Valor de p } \\
\cline { 2 - 5 } & $\mathbf{n}=\mathbf{3 3}$ & $\mathbf{\%}$ & $\mathbf{n}=\mathbf{4 2}$ & $\mathbf{\%}$ & \\
\hline HPV Negativo & 13 & 39,4 & 31 & 73,8 & $0,0027^{*}$ \\
HPV Positivo & 20 & 60,6 & 11 & 26,2 & $0,0027^{*}$ \\
Tipo 16 & 14 & 42,4 & 8 & 19,0 & $0,0273^{*}$ \\
Tipo 18 & 5 & 15,2 & 1 & 2,4 & $0,0430^{*}$ \\
Outro tipo & 1 & 3,0 & 2 & 4,8 & 0,7040 \\
\hline
\end{tabular}

* teste do qui-quadrado. Outro tipo: HPV tipos 6, 11, 31, 33, 35, ocorrendo simultaneamente em diversas combinações. $H_{0}$ : não há diferença significativa entre as proporções do HPV nos Grupos Teste e Controle, $p_{1}=p_{2} . H_{1}$ : há diferença significativa entre as proporções do HPV nos Grupos Teste e Controle, $p_{1} \neq p_{2}$. Nivel de decisão: 0.05. 
No GC, a prevalência do HPV $=0,262$ com IC $95 \%=[0,129,0,395]$, portanto, existe $95 \%$ de confiança de que entre 12,9 e $39,5 \%$ dos indivíduos sem câncer apresentam HPV. Neste mesmo grupo, ocorre a prevalência do HPV tipo 16=0,167 com IC $95 \%=[0,054-0,279]$. Assim, estima-se com 95\% de confiança que 5,4 e 27,9\% dos indivíduos sem câncer apresentam HPV tipo 16.

De acordo com a Tabela 2, a distribuição dos graus de diferenciação celular entre os indivíduos do GT não difere entre as categorias HPV positivo $(n=20)$ e HPV negativo $(n=13)$, ou seja, não há evidências suficientes para se concluir que os graus de diferenciação celular estejam associados significativamente com as categorias do HPV (positivo e negativo), nos indivíduos com câncer. $O$ valor de p igual a 0,7924 não é significante, indicando que deve-se aceitar a hipótese nula.

Na Tabela 3, os resultados mostram que 40,0\% dos indivíduos amostrados apresentam diferenciação celular de grau III, 70,0\% dos indivíduos HPV positivos possuem HPV tipo 16, e 25\% dos indivíduos apre-

Tabela 2. Distribuição dos graus de diferenciação celular conforme a presença do HPV no Grupo Teste de amostras coletadas no serviço de cirurgia abdominopélvica do HOL em Belém - janeiro de 1998 a dezembro de 2000.

\begin{tabular}{lcccc}
\hline $\begin{array}{l}\text { Diferenciação } \\
\text { celular }\end{array}$ & \multicolumn{2}{c}{$\begin{array}{c}\text { HPV POS } \\
(\mathbf{n}=\mathbf{2 0})\end{array}$} & \multicolumn{2}{c}{$\begin{array}{c}\text { HPV NEG } \\
(\mathbf{n}=\mathbf{1 3})\end{array}$} \\
\hline 1 & 5 & $25,0 \%$ & 4 & $30,8 \%$ \\
2 & 6 & $30,0 \%$ & 5 & $38,5 \%$ \\
3 & 8 & $40,0 \%$ & 3 & $23,1 \%$ \\
4 & 1 & $5,0 \%$ & 1 & $7,7 \%$ \\
\hline
\end{tabular}

Valor de p: 0,7924 (qui-quadrado=1,037, $G L=3$ ). $H_{0}$ : os niveis de diferenciação celular independem do HPV ser positivo ou negativo. $H_{I}$ : os níveis de diferenciação celular dependem do HPV ser positivo ou negativo. Nivel de decisão: alfa=0,05. sentam diferenciação celular grau III e HPV tipo 16. A tabela revela alguns padrões importantes: o HPV tipo 16 está presente nos quatro graus de diferenciação celular, o que não ocorre com o HPV tipo 18 . O valor de p não foi significante nos tipos 16, 18, 31, 33 e 35 de HPV. Assim, estes tipos de HPV não estão associados significativamente com os graus de Broders, nos pacientes acometidos por câncer.

A distribuição dos níveis de estadiamento entre os indivíduos do GT não difere entre as categorias HPV positivo $(n=20)$ e negativo $(n=13)$, o valor de $p$ igual a 0,3136 não é significante, indicando que devese aceitar a hipótese nula.

Um exame da Tabela 4 revela que $70,0 \%$ dos indivíduos amostrados ocorrem no nível II de estadiamento e, também, 70,0\% dos indivíduos com HPV positivo possuem HPV tipo 16, e 55\% dos indivíduos possuem HPV tipo 16 e estão no nível II de estadiamento. Além disso, a tabela mostra que o HPV tipo 16 está presente em quase todos os quatro níveis de estadiamento, o que não ocorre com o HPV tipo 18.

Tabela 4. Distribuição dos níveis de estadiamento conforme a presença do HPV no Grupo Teste de pacientes do serviço de cirurgia abdominopélvica do HOL em Belém - janeiro de 1998 a dezembro de 2000.

\begin{tabular}{lcccc}
\hline $\begin{array}{l}\text { Estadiamento } \\
\boldsymbol{T N M}\end{array}$ & \multicolumn{2}{c}{$\begin{array}{c}\boldsymbol{H P V} \boldsymbol{P O S} \\
(\boldsymbol{n}=\mathbf{2 0})\end{array}$} & \multicolumn{2}{c}{$\boldsymbol{H P V} \boldsymbol{N E G}$} \\
$(\boldsymbol{n}=\mathbf{1 3})$
\end{tabular}

Valor de p: 0,3136 (qui-quadrado=3,556, $G L=3$ ). Entre os casos de HPV NEG, houve um em que o estadiamento não foi avaliado. $H_{0}$ : os niveis de estadiamento independem do HPV ser positivo ou negativo. $H_{1}$ : os niveis de estadiamento dependem do HPV ser positivo ou negativo. Nivel de decisão: alfa=0,05.

Tabela 3. Diferenciação celular no Grupo Teste, com resultado positivo para o HPV, de amostras coletadas no serviço de cirurgia abdominopélvica do HOL em Belém - janeiro de 1998 a dezembro de 2000.

\begin{tabular}{|c|c|c|c|c|c|c|c|c|c|}
\hline \multirow{3}{*}{ Tipo de HPV } & \multicolumn{8}{|c|}{ Diferenciação celular - HPV Positivo } & \multirow{3}{*}{ Total (\%) } \\
\hline & \multicolumn{2}{|c|}{$I$} & \multicolumn{2}{|c|}{ II } & \multicolumn{2}{|c|}{ III } & \multicolumn{2}{|c|}{$I V$} & \\
\hline & $\boldsymbol{n}$ & $\%$ & $\boldsymbol{n}$ & $\%$ & $\boldsymbol{n}$ & $\%$ & $\boldsymbol{n}$ & $\%$ & \\
\hline HPV tipo 16 & 5 & 25,0 & 3 & 15,0 & 5 & 25,0 & 1 & 5,0 & 70,0 \\
\hline HPV tipo 18 & 0 & 0,0 & 3 & 15,0 & 2 & 10,0 & 0 & 0,0 & 25,0 \\
\hline HPV outro tipo & 0 & 0,0 & 0 & 0,0 & 1 & 5,0 & 0 & 0,0 & 5,0 \\
\hline Total & 5 & 25,0 & 6 & 30,0 & 8 & 40,0 & 1 & 5,0 & 100,0 \\
\hline
\end{tabular}

Valor de p: 0,7490; $n$ : número; Outro tipo: HPV tipos 31, 33, 35 ocorrendo simultaneamente. Percentagens baseadas no total geral (n=20). 
Tabela 5. Distribuição dos tipos do HPV conforme o estadiamento no Grupo Teste com HPV positivo $(n=20)$, de amostras coletadas no serviço de cirurgia abdominopélvica do HOL em Belém - janeiro a 1998 a dezembro de 2000.

\begin{tabular}{lcc}
\hline \multirow{2}{*}{ Tipo de HPV } & \multicolumn{2}{c}{ Estadiamento $\boldsymbol{T N M}$} \\
\cline { 2 - 3 } & $\boldsymbol{I}$ e II $(\boldsymbol{n}=\mathbf{1 4})$ & III $\boldsymbol{e}$ IIIb $(\boldsymbol{n}=\mathbf{6})$ \\
\hline HPV tipo 16 & $11(78,5 \%)$ & $3(50,0 \%)$ \\
HPV tipo 18 & $3(21,5 \%)$ & $2(33,3 \%)$ \\
HPV outro tipo & $0(0 \%)$ & $1(16,7 \%)$ \\
\hline
\end{tabular}

Valor de p: 0,2161. Outro tipo: HPV tipo 31, 33, 35 ocorrendo simultaneamente. $H_{0}$ : os tipos do HPV apresentam as mesmas proporções entre as duas categorias de estadiamento. $H_{1}$ : os tipos do HPV não apresentam as mesmas proporções entre as duas categorias de estadiamento. Nível de decisão: alfa=0,05.

Na Tabela 5, o valor de p não foi significante para atestar a associação entre os tipos do HPV e as duas categorias de estadiamento, ou seja, não há evidências suficientes para se concluir que esses tipos do HPV estejam associados significativamente com os estadiamentos I e II (câncer menos agressivo) ou com os estadiamentos IIIa e IIIb (câncer mais agressivo), em indivíduos com câncer.

\section{DISCUSSÃO}

Apesar das dificuldades encontradas no processo de amostragem desta investigação, optou-se por realizar um modelo de estudo do tipo analítico, ou seja, foram criados dois grupos de análise, o que permitiu aplicar testes estatísticos adequados e obter conclusões pertinentes.

Embora o tamanho amostral seja adequado, a distribuição dos pacientes nos grupos de comparação não foi homogênea, visto que, no GT, verificou-se presença significantemente maior de pacientes do gênero feminino $(\mathrm{p}=0,03)$. Isso não ocorreu com a variável idade, que se mostrou comparável nos dois grupos. Essas circunstâncias, entretanto, não comprometeram o resultado da pesquisa.

Foi observado ainda que, na literatura, há pouca referência de trabalhos com GC apresentando tratamento estatístico correto quanto à paridade com relação ao gênero, à idade e aos dados epidemiológicos. Dos estudos analisados, somente um apresentou o GC bem pareado 6 .
Outro fator que limitou as conclusões deste estudo foi a indisponibilidade dos dados clínicos de infecção por HIV dos pacientes estudados.

O principal fator para o desenvolvimento de CCE do canal anal em pacientes com HIV é o tempo de infecção por este vírus. Embora os dados clínicos disponíveis não indicassem infecção por HIV nas pessoas avaliadas neste estudo, somente o teste laboratorial poderia dar essa certeza ${ }^{19}$.

Apesar de transcorridos nove anos entre a realização da análise dos dados e a coleta das amostras, esse fator não interferiu no método de extração e tipagem do DNA do HPV, realizadas em 2003, considerando que as amostras biológicas coletadas foram estocadas de forma adequada e enviadas em formol parafinado para o Instituto Ludwig, em São Paulo, no qual se confirmou a qualidade do material de estudo.

Para o diagnóstico de HPV, empregou-se a PCR complementada pelo dot blot, por serem técnicas consagradas para identificação e tipagem do HPV em $\mathrm{CCE}^{24,25}$.

Houve associação significante entre a presença do HPV e o CCE do canal anal, o que está de acordo com a maioria dos dados da literatura, indicando que, na carcinogênese do câncer de canal anal, o fator viral, associado possivelmente à imunidade local e sistêmica, pode ser importante referência para a tomada de decisões terapêuticas em pacientes portadores de infecção clínica e subclínica por HPV, principalmente pelos tipos virais de HPV que foram identificados neste estudo. Tais medidas poderiam impedir o desenvolvimento para o câncer invasivo dessas lesões.

Os tipos de HPV encontrados mais frequentemente associados ao CCE do canal anal foram os 16 e 18.

Foram identificados 13 estudos, realizados no período de 1991 a 2007, que usaram metodologia de identificação do DNA por PCR e, entre estes, somente três são analíticos e apresentam similaridade com a presente investigação, enquanto os outros dez são descritivos e analisam apenas a ocorrência de HPV em grupo de pacientes com CCE do canal anal.

Dos três estudos de caráter analítico, vale ressaltar o primeiro, cujos pesquisadores, ao analisarem uma amostra constituída de 41 pacientes com câncer anal e 12 no GC, encontraram, respectivamente, 80 e $0 \%$ de $\mathrm{HPV}^{26}$. Na segunda investigação, foram identificados 
99 pacientes com CCE, entre os quais 13 faziam parte do GC, e foi observada a presença do vírus em $81 \%$ no grupo com câncer e $0 \%$ no $\mathrm{GC}^{27}$. Com 21 biópsias de CCE e 21 no GC, os pesquisadores do terceiro estudo relataram a presença do vírus em $100 \%$ das biópsias do grupo câncer, já no GC, da mesma forma que nas outras pesquisas, o resultado foi negativo. Esses autores também utilizaram outro GC e, dos 21 pacientes que o constituíram, elegeram 13 do grupo com câncer para analisar a presença de HPV em fragmentos de epitélio normal próximo ao tumor, não tendo encontrado presença viral ${ }^{6}$.

Foi observado nesses estudos que a prevalência de HPV no grupo com câncer variou entre 75 e 100\%, enquanto que neste estudo foi de $60,6 \%$ - possivelmente em razão da qualidade da parafina utilizada -, muito embora os presentes achados estejam de acordo com a literatura ${ }^{28}$, que demonstrou uma variação de prevalência entre 36 a 90\% de HPV, em CCE. De acordo com a literatura, assim como nesta pesquisa, o tipo 16 foi o mais prevalente.

Em virtude do tamanho amostral, destaca-se, dentre as pesquisas realizadas, o estudo do tipo casocontrole, no qual observou-se a infecção por HPV em $88 \%$ de 388 pacientes com CCE de ânus, sendo o HPV 16 o tipo responsável por $73 \%$ dos casos de CCE invasivo. O GC foi constituído por 20 pacientes portadores de câncer colorretal e, em todos eles, o resultado foi negativo para $\mathrm{HPV}^{29}$.

Não houve correlação significante entre os tipos encontrados de HPV, o grau de diferenciação celular e o estadiamento do CCE do canal anal. É possível que o tamanho amostral desta pesquisa não tenha poder estatístico para indicar essa correlação. A probabilidade de o HPV 16 estar relacionado com um carcinoma de comportamento biológico mais agressivo pode ser viável. Esse tipo viral está mais correlacionado com a ASIL de alto grau, e os outros tipos são geralmente mais detectados na ASIL de baixo grau ${ }^{29}$. Por isso, nessa pesquisa, da mesma forma que na presente, a presença ou a ausência de HPV não pôde ser referida com o prognóstico.

Foi estabelecida uma correlação entre o HPV e o grau de diferenciação celular, sem distinguir os tipos virais, apresentando-se em amostras de 56 pacientes os seguintes resultados: 9,3\% de HPV em tumores grau I; 44,4\%, II; e 46,3\%, III ${ }^{14}$. Nesta investigação, foi apresentada não apenas a correlação entre o $\mathrm{CCE}$ do canal anal e o agente viral, como também com o tipo de HPV, tentando demonstrar se havia influência do tipo viral nos graus de diferenciação celular e estadiamento.

Os achados desta pesquisa mostraram que o CCE está associado à presença do HPV e que os tipos $16 \mathrm{e}$ 18 são os mais frequentes.

Ainda que sejam reconhecidas as limitações amostrais próprias de uma pesquisa dessa natureza, acredita-se que as conclusões desta investigação podem constituir importante contribuição científica para o melhor conhecimento dos fatores de risco relacionados com essa afecção. Como trata-se de uma doença de origem multifatorial, certamente é necessário investigar, com profundidade, outros fatores envolvidos, o que poderá levar a um melhor entendimento tanto do processo de carcinogênese, quanto dos aspectos epidemiológicos dessa doença.

O verdadeiro papel desempenhado pelo HPV na gênese do CCE do canal anal ainda merece estudos mais aprofundados, mas já existem sinais do possível valor do emprego de vacinas e medidas profiláticas apropriadas.

O conjunto de informações gerado pelas novas investigações sobre o assunto em questão pode servir de base para a implementação de políticas adequadas a essa área da saúde, tendo em vista a prevenção e o tratamento de afecção tão prevalente no Brasil.

\section{CONCLUSÕES}

Com base nos resultados obtidos nesta investigação, é possível concluir que o CCE do canal anal está associado à presença do HPV, e os tipos 16 e 18 são os mais frequentemente encontrados no CCE do canal anal.

\section{AGRADECIMENTOS}

Os autores são gratos a José Carlos Mann Prado e João Simão Sobrinho pela realização das hibridizações moleculares, que determinaram os tipos de HPV envolvidos nesta série de tumores, e à doutora Maria Vanda Catão Arnaud, chefe do Departamento de Patologia do Hospital Ophir Loyola, pelas análises histopatológicas. 
ABSTRACT: Objective: To identify the most predominant types of human papillomavirus (HPV) in carriers of the anal canal carcinoma (ACC), relating them to the cell differentiation and lesion staging degree, in patients from Belém, Pará, Brazil, between 1998 and 2000. Methods: A case-control study was conducted with 75 patients, divided into Test Group, with 33 carriers of the anal canal carcinoma, and Control Group, with 42 carriers of non-neoplastic diseases of the anal canal. The methods employed to identify the viral types were the polymerase chain reaction and the dot blot. The Fisher's exact test was used to assess the HPV occurrence. The distribution of HPV types was analyzed by $3 \times 2$ contingency tables, representing the distribution of HPV types. For hypothesis testing, the significance level $\alpha=\mathbf{0 . 0 5}$ was previously established for rejection of the null hypothesis. Results: HPV was significantly prevalent $(p=0.0027)$ in the Test $(60.6 \%)$ and Control Groups $(26.2 \%)(p=0.0027)$. The most prevalent viral types were HPV $16(42.4 \%)$ and 18 $(\mathbf{1 5 . 2 \%})$. Significant differences related to the prevalence of HPV 16 and 18 were verified between both groups $(p=0.027$ and $p=0.043$, respectively). In the Control Group, HPV 16 was found in $19.0 \%$, whereas HPV 18 was observed in $2.4 \%$. In the Test Group, we evaluated the distribution of HPV types according to the staging and degree of cell differentiation, and found no significant differences between the results of the different groups. Conclusion: Squamous cell carcinoma of the anal canal is associated with the HPV presence, and the 16 and 18 types are the most frequently found.

Keywords: papillomavirus infections; carcinoma, squamous cells; anal canal; papilloma.

\section{REFERÊNCIAS}

1. Fenger C. Prognostic factors in anal carcinoma. Pathology 2002;34(6):573-8.

2. Daling JR, Weiss NS, Hislop TG, Maden C, Coates RJ, Sherman KJ, et al. Sexual practices, sexually transmitted diseases, and the incidence of anal cancer. N Engl J Med 1987;317(16):973-7.

3. Goldie SJ, Kuntz KM, Weinstein MC, Freedberg KA, Welton ML, Palefsky JM. The clinical effectiveness and costeffectiveness of screening for anal squamous intraepithelial lesions in homosexual and bisexual HIV-positive men. J Am Med Assoc 1999;281(19):1822-9.

4. Licitra L, Spinazzé S, Doci R, Jeffry ETR, Tanum G, Ducreux M. Cancer of the anal region. Crit Rev Oncol Hematol 2002;43(1):77-92.

5. Frisch M, Glimelius B, Wohlfahrt J, Adami HO, Melbye M. Tobacco smoking as a risk factor in anal carcinoma: an antiestrogenic mechanism. $J$ Natl Cancer Inst 1999;91(8):708-15.

6. Youk EG, Ku JL, Park JG. Detection and typing of human papillomavirus in anal epidermoid carcinomas: sequence variation in the E7 gene of human papillomavirus type 16 . Dis Colon Rectum 2001;44(2):236-42.

7. Doorbar J. The papillomavirus life cycle. J Clin Virol 2005;32 Suppl 1:S7-15.

8. Villa LL. Human papillomaviruses and cervical cancer. Cancer Res 1997;71:321-41.

9. Fenger C. Anal canal. In: Sternberg SS, editor. Histology for Pathologists. 2nd ed. Philadelphia: Lippincott-Raven; 1997. p. 551-69.

10. Wendell-Smith CP. Anorectal nomenclature. Fundamental terminology. Dis Colon Rectum 2000;43(10):1349-58.

11. Gervaz P, Allal AS, Villiger P, Bubller L, Morel P. Squamous cell carcinoma of the anus: another sexually transmitted disease. Swiss Med Wkly 2003;133:353-9.

12. Souza PSA, Villa LL. Genetic susceptibility to infection with human papillomavirus and development of cervical cancer in women in Brasil. Mutat Res 2003;544(2-3):375-83.

13. Cavalcanti SMB, Zardo LG, Passos MRL, Oliveira LHS. Epidemiological Aspects of Human Papillomavirus infection and Cervical Câncer in Brasil. J Infect 2000;40(1):80-7.

14. Noffsinger AE, Hui YZ, Suzuk L, Yochman Lk, Miller MA, Hurtubise $\mathrm{P}$, et al. The relationchip of human papillomavirus to proliferation and ploidy in carcinoma of the anus. Cancer 1995;75(4):958-67.

15. Hiller $\mathrm{T}$, Poppelreuther $\mathrm{S}$, Stubenrauch $\mathrm{F}$, Iftner $\mathrm{T}$. Comparative analysis of 19 genital human papillomavirus types with regard to p53 degradation, immortalization, phylogeny, and epidemiologic risk classification. Cancer Epidemiol Biomarkers Prev 2006;15(7):1262-7.

16. Tilston P. Anal human papillomavirus and anal cancer. J Clin Pathol 1997;50(8):625-34.

17. Ramanujam PS, Venkatesh KS, Barnett TC, Fietz MJ. Study of human papillomavirus infection in patients with anal squamous carcinoma. Dis Colon Rectum 1996;39(1):37-9.

18. Palefsky JM. Cutaneous and genital HPV-associated lesions in HIV-infected patients. Clin Dermatol 1997;15(3):439-47.

19. Palefsky JM, Holly EA, Ralston ML, Jay N. Prevalence and risk factors for human papillomavirus infection of the anal canal in human immunodeficiency virus (HIV)positive and HIV-negative homosexual men. J Infect Dis 1998; 177:361-7.

20. Johnson LG, Madeleine MM, Newcomer LM, Schwartz SM, Daling JR. Anal cancer incidence and survival: the surveillance, epidemiology, and end results experience, 1973-2000. Cancer 2004;101(2):281-8.

21. Coutinho JRH. Rastreamento de lesões pré-neoplásicas do ânus. Citologia anal e anuscopia de alta resolução novas armas para prevenção. Rev Col Bras Cir 2006;33(5):311-7.

22. Instituto Nacional de Câncer (INCA). Estatística do câncer: incidência: 2005. [Acesso em 12 mar 2006]. Disponível em: http://bvsms.saude.gov.br/bvs/publicacoes/estimativa versaofinal.pdf. 
23. Ayres M, Ayres M Jr, Ayres DL, Santos AAS. Bioestat Versão 4.0. Belém: Sociedade Civil Mamirauá, CNPq; 2005.

24. Mant C, Kell B, Best JM, Cason J. Polymerase chain reaction protocols for the detection of DNA from mucosal human papillomavirus types $-6,-11,-16,-18,-31$ and -33 . J Virol Methods 1997;66:169-78.

25. Husnjak K, Grce M, Magdié L, Pavelic K. Comparison of five different polymerase chain reaction methods for detection of human papillomavirus in cervical cell specimens. J Virol Methods 2000;88(2):125-34.

26. Crook T, Wrede D, Tidy J, Scholefield J, Crawford L, Vousden KH. Status of c-myc, p53 and retinoblastoma genes in human papillomavirus positive and negative squamous cell carcinomas of the anus. Oncogene 1991;6(7):1251-7.
27. Holm R, Tanum G, Karlsen F, Nesland JM. Prevalence and physical state of human papillomavirus DNA in anal carcinomas. Mod Pathol 1994;7(4):449-53.

28. Frisch M. On the etiology of anal squamous carcinoma. Dan Med Bull 2002;49(3):194-209.

29. Frisch M, Glimelius B, van den Brule AJ, Wohlfahrt J, Meijer CJ, Walboomers JM, et al. Sexually transmitted infection as a cause of anal cancer. N Engl J Med 1997;337(19):1350-8.

\section{Endereço para correspondência:}

PAULO CARDOSO SOARES

Hospital Ophir Loyola

Avenida Magalhães Barata, 992

CEP: 66060-281

E-mail: pcsoares@amazon.com.br 